\title{
Iniciação científica: uma metodologia de avaliação
}

\author{
Pierre Ohayon \\ Lygia V. de Aquino \\ Ana Lúcia G. Maravalhas \\ Beatriz B. Marques dos Santos \\ Edna A. Barreto \\ Marlene J. S. Bezerra
}

\section{Resumo}

Apresentamos a construção de um modelo de avaliação para programas de iniciação científica em nível médio, levandose em consideração a legislação vigente e as demandas sociais. Tais elementos enfocam a busca de conhecimento e a formação do indivíduo cidadão e produtivo, para garantir sua participação na sociedade de forma autônoma e crítica. A elaboração de indicadores avaliativos buscou contribuir com a consolidação de programas voltados para a preparação de jovens pesquisadores e com seu aprimoramento qualitativo.

Palavras-chave: Iniciação científica. Avaliação. Programas. Metodologia. Indicadores quantitativos e qualitativos. Instrumentos.
Abstract

Scientific initiation: en evaluation methodology

The construction of an evaluation model for high school scientific initiation programs is proposed, regarding educational legislation and social demands, mainly those allowing the search for knowledge and the rising of a productive citizen in such a way to ensure his autonomous and critical participation. The article intends to contribute to the consolidation of young researchers in oriented programs that may contribute to their qualitative improvement, through the making of useful evaluation indicators.

Keywords: Scientific Initiation programs. Evaluation. Methodology. Quantitative and qualitative indicators. Operational resources. 


\section{Resumen}

Iniciación científica: una metodologia de evaluación

Empezamos la construcción de un modelo de evaluación para programas de iniciación científica de nivel intermediario, teniendo en consideración la legislación actual y las demandas sociales, y buscando al conocimiento y formación del individuo ciudadano y productivo, para que se garantice su participación en la sociedad de forma autónoma y críica. Se pretende, aquí, a partir de la elaboración de indicadores estimativos, contribuir a la consolidación de programas dirigidos a la preparación de jóvenes investigadores y su perfeccionamiento cualitativo.

Palabras clave: Iniciación Científica. Evaluación. Programas. Metodología. Indicadores cuantitativos y cualitativos. Instrumentos.

\section{Introdução}

A elaboração de uma proposta de metodologia de avaliação, resultado de discussões no decorrer de uma disciplina no Doutorado em Educação da Universidade Federal do Rio de Janeiro - UFRJ, visando ao Programa de Iniciação Científica do Colégio de Aplicação da UFRJ, levou à difícil tarefa de pensar na formação científica de jovens do ensino médio, em um momento histórico no qual o processo de globalização torna vertiginosa a busca pelo conhecimento e o acesso a informações. Nesse contexto, o conhecimento figura como elemento principal não apenas da garantia de maior cidadania, quanto alcança status de troca, na medida em que se torna elemento central diante das mudanças apresentadas pela revolução tecnológica do último século.
As reformas educacionais impulsionadas pelo cenário globalizado da sociedade impuseram ao ensino médio novas demandas de formação, como podemos observar nas orientações dos Parâmetros Curriculares Nacionais - PCN, para esse nível de ensino, quando coloca que: "a formação do aluno deve ter como alvo principal a aquisição de conhecimentos básicos, a preparação científica e a capacidade de utilizar as diferentes tecnologias relativas às áreas de atuação." (BRASIL, 1999, p. 14, grifo do autor). Nesta reforma curricular, afirma-se ainda que a aquisição de mais saberes "[...] favorece o desenvolvimento da curiosidade intelectual, estimula o senso crítico e permite compreender o real, mediante a aquisição da autonomia na capacidade de discernir" (BRASIL, 1999, p. 34).

Este projeto pretende contribuir com a consolidação de programas cujo perfil esteja afinado com a preparação de jovens pesquisadores, o que nos levou a apresentar indicadores avaliativos que possam auxiliar seu aprimoramento qualitativo.

Como apontado anteriormente, a própria reforma da educação brasileira salienta a necessidade de uma educação que venha atender ao novo contexto social. Nesse sentido, a Lei de Diretrizes e Bases da Educação - LDB, Lei n 9.394, de 20 de dezembro de 1996 (BRASIL, 1996), apresenta uma proposta de organização curricular baseada em projetos interdisciplinares capazes de atender ao currículo por competências, às noções de flexibilidade, diversidade, contextualização e temas transversais assim como ao princípio da autonomia intelectual e pensamento crítico (LDB, Art. 35, inciso III). A formação escolar supera a simples transmissão de conhecimentos e cultura para a construção de saberes em situações reais de aprendizagem, sendo a educação vista como pro- 
cesso e não como produto.

O significado de educação geral no nível médio, segundo o espírito da LDB, nada tem a ver com o ensino enciclopedista e academicista dos currículos de Ensino Médio tradicionais [...] em lugar de estabelecer disciplinas ou conteúdos específicos, destaca competências de caráter geral, dentre as quais a capacidade de aprender é decisiva [...] convoca a constituição de uma identidade autônoma. (BRASIL, 1999, p. 128-129).

Os quatro princípios propostos pela Comissão Internacional sobre a Educação para o século XXI contido no relatório para a UNESCO (DELORS, 2003), e incorporados nas determinações da Lei $n^{\circ} 9.394$ (BRASIL, 1996), estabelecem que a educação deve ser estruturada em quatro eixos: aprender a conhecer, aprender a fazer, aprender a viver e aprender a ser. Portanto, a preocupação com a aprendizagem é permanente, pelo "desenvolvimento das competências para continuar aprendendo de forma autônoma e crítica, em níveis mais complexos de estudo, aprender a aprender é a competência fundamental" (BRASIL, 1999, p. 23); este é o princípio que norteia toda a formação do jovem desse século.

Nessa proposta, a organização do currículo deve-se fundamentar na idéia da aprendizagem permanente, onde o aluno aprende a buscar o conhecimento e, já que se "supõe desenvolver a capacidade de assimilar mudanças tecnológicas e adaptar-se a novas formas de organização do trabalho, faz-se necessário ampliar oportunidades de continuar aprendendo." (BRASIL, 1999, p. 105).

O referido relatório da UNESCO apresenta, também, uma proposta de educação capaz de conscientizar o jovem sobre suas raízes culturais e históricas, ao mesmo tempo em que reorganiza o ensino a fim de ampliar o conhecimento sobre o mundo em que vivemos e a diversidade de culturas e relações do ser humano com seu meio ambiente. $\bigcirc$ relatório destaca, ainda, a importância da construção da identidade de cada um a partir do conhecimento de sua cultura, reforçando o sentimento de pertencer a um grupo e impedir que o jovem se feche em si mesmo, para que compreenda a diversidade.

A concepção do Programa de Iniciação Científica Júnior justifica-se pela importância da aprendizagem permanente para acompanhar as transformações do mundo atual e da metodologia científica, como segue:

Este tipo de aprendizagem que visa não tanto à aquisição de um repertório de saberes codificados, mas antes ao domínio dos próprios instrumentos do conhecimento pode ser considerado, simultaneamente, como um meio e como uma finalidade da vida humana. Meio, porque se pretende que cada um aprenda a compreender o mundo que o rodeia, pelo menos, na medida em que isso lhe é necessário para viver dignamente, para desenvolver suas capacidades profissionais, para se comunicar. Finalidade, porque seu fundamento é o prazer de compreender, de conhecer, de descobrir [...] $\bigcirc$ aumento dos saberes, que permite compreender melhor 0 ambiente sob seus diversos aspectos, favorece o despertar da curiosidade intelectual, estimula o sentido crítico e permite compreender o real, mediante a aquisição de autonomia na capacidade de discernir. Deste ponto de vista, é essencial que cada criança, esteja onde 
estiver, possa ter acesso, de forma adequada, às metodologias científicas de modo a tornar-se para toda a vida "amiga da ciência". (DELORS, 2003, p. 91).

\section{Justificativa}

A criação de uma metodologia de avaliação dos programas de iniciação científica faz-se necessária para averiguar o estágio em que se encontra a instituição e que, através desse processo, seja possível controlar a eficácia de execução desses programas, de acordo com Natarajan (apud AGUILAR; ANDER-EGG, 1994). Este afirma que a avaliação só terá utilidade se servir à melhoria de um programa, por meio do conhecimento de suas qualidades e fraquezas para poder modificá-lo à medida que for preciso, eliminando os erros e corrigindo-os. Defende-se, no entanto a necessidade de uma avaliação contínua, que não se enfraqueça com as mudanças de liderança ou desmembramento de equipes, enaltecendo, assim, o caráter formativo que permitirá a melhoria do que está sendo posto em prática. Como propõe Patton (1986), esta avaliação deverá ser centrada na utilização, que consiste em adaptar continuamente os métodos selecionados pelo avaliador às situações particulares.

Para Weiss (apud AGUILAR; ANDER-EGG, 1994), a avaliação analisa a relação progra$\mathrm{ma} /$ necessidade social, por meio da medida do grau e da profundidade em que seus fins são alcançados e, portanto, das necessidades satisfeitas e dos problemas solucionados.

Dessa forma, esta metodologia de avaliação oferecerá condições para a melhoria da formação do aluno em processo de iniciação científica. Uma metodologia de avaliação permitirá identificar as insuficiências e potencialidades do processo, auxiliando assim a instituição pelo autoconhecimento de suas fraquezas e fortalezas. Somente a partir de um diagnóstico substantivo das dificuldades e das causas, a instituição poderá desempenhar sua função de locus de aprendizagem e de produção do conhecimento.

A introdução de medidas de ajuste dentro de um programa representa o feedback, que é o que dá valor ao programa. Portanto, a criação desta metodologia servirá para prestar ajuda a essas instituições que oferecem o programa, para que as mesmas possam atender efetivamente às necessidades dos educandos envolvidos, assim como as do sistema educacional que os incorpora, introduzindo modificações em seu projeto, melhorando a metodologia utilizada, ou a estratégia de desenvolvimento do programa em questão. A partir da avaliação, a instituição poderá definir melhor suas prioridades e ações de correção, para superar os equívocos e insuficiências. Poderá revisar seus projetos e até mesmo o seu compromisso com a pesquisa.

Os alunos, professores e outros profissionais envolvidos poderão tomar conhecimento de seu desempenho, podendo assim aprimorá-lo.

A metodologia propõe servir a medir o estágio da iniciação científica com respeito ao nível de implementação de práticas consideradas fundamentais para garantir o seu desempenho, buscando o conhecimento de seus valores, objetivos e prioridades.

\section{Objetivos}

Os objetivos a que nos propusemos foram:

- Elaborar instrumentos de coleta de dados visando a:

- verificar a adequação do planejamento e 
conceituação do programa com sua aplicação;

- verificar a eficiência da cobertura, estrutura e ambiente organizacional do Programa para adequação das propostas expressas em seus objetivos;

- obter um panorama da modificação nos alunos que participam do programa quanto à utilização de aspectos metodológicos no processo de construção de conhecimentos;

- fazer um levantamento dos resultados obtidos, com ênfase na verificação de construção de uma cultura metodológica e de retorno social, manifestado em sua contextualização;

- construir indicadores que possam apontar o nível de acertos e de pontos a serem corrigidos ao longo da implementação do programa;

- confeccionar tabelas de referência para exame dos indicadores de modo a obter elementos para confirmação ou revisão de procedimentos relativos ao Programa.

\section{Metodologia}

Foram confeccionados instrumentos de coleta de dados, com perguntas estruturadas abertas, semi-abertas e fechadas, dirigidos aos alunos participantes, Coordenadores e Pesquisadores-Orientadores, que se encontram no Anexo. A elaboração dos mesmos se deu a partir dos objetivos propostos para o programa do Colégio de Aplicação da UFRJ, explicitados nos documentos fornecidos pelo Núcleo de Iniciação $\mathrm{Ci}$ entífica Júnior, e modelos de análise dos dados obtidos através destes instrumentos.

Propõe-se que o levantamento de dados inicial se dê com o uso dos instrumentos apresentados nos Anexos. A partir da tabulação dos dados dos mesmos, podem ser constituídos indicadores que, de acor- do com a pontuação e comparação com os resultados esperados, possam apontar o nível de acertos obtido e os pontos a serem corrigidos ao longo das etapas seguintes do Programa.

A estruturação do modelo de avaliação fundamenta-se na construção de um banco de dados composto por um elenco de critérios, a saber:

1. Foco nos insumos

2. Foco no processo

3. Foco na qualidade acadêmica

4. Foco nos resultados

As variáveis sugeridas são:

1. total de alunos matriculados na escola;

2. total de alunos candidatos ao programa;

3. total de alunos selecionados no programa;

4. total de alunos concluintes do programa;

5. alunos que apresentaram trabalhos científicos no decorrer ou ao término do programa;

6. carga horária cumprida pelos alunos;

7. carga horária pretendida pelo programa;

8. média anual do aluno no ano anterior ao programa;

9. média anual do aluno ao término do ano em que participou do programa;

10. nível de satisfação dos docentes com o desempenho do aluno participante do programa em suas respectivas disciplinas;

11. nível de satisfação do aluno com sua participação no programa;

12. percentual de metodologia desejável trabalhada pelo aluno ao longo de sua participação no programa;

13. impressões dos alunos sobre sua participação no programa em relação ao 
ambiente de trabalho;

14. impressões dos alunos sobre sua participação no programa em relação à equipe de trabalho;

15. impressões dos alunos sobre sua participação no programa, em relação a seu desempenho individual;

16. impressões dos orientadores sobre a participação dos alunos no programa em relação ao ambiente de trabalho;

17. impressões dos orientadores sobre a participação dos alunos no programa em relação à equipe de trabalho;

18. impressões dos orientadores sobre as atitudes observadas, em relação ao aluno durante a duração do programa;

19. impressões dos orientadores sobre o desempenho dos alunos durante sua participação no programa;

20. impressões dos alunos sobre sua participação no programa;

21. dados sobre estudo-pesquisa para critérios de avaliação de insumos;

22. dados sobre diagnóstico para critérios de avaliação de insumos;

23. dados sobre plano do programa para critérios de avaliação de insumos;

24. dados sobre cobertura para critérios de avaliação de insumos;

25. dados sobre cobertura para critérios de avaliação de processo;

26. dados sobre rendimento de pessoal para critérios de avaliação de processo;

27. dados sobre estrutura e ambiente organizacional para avaliação de processo;

28. dados sobre avaliação de eficiência e eficácia do programa para avaliação de resultados.

A partir destas variáveis, faz-se a construção dos indicadores. Os indicadores de desempenho têm por finalidade reunir relações entre os dados colhidos, visando à obtenção de resultados percentuais com faixas conceituais e número de pontos correspondentes, para favorecer uma análise imediata dos resultados obtidos, cujos conceitos apontarão as possíveis correções de procedimentos. (BOCLIN, 2002).

Os indicadores de desempenho construídos são:

1. Foco nos insumos

(1.1)

Alunos matriculados na escola $=\mathbb{I N}$ DICADOR DE ATRATIVIDADE

Alunos que se candidataram

(1.2)

Respostas positivas em relação a avaliação do planejamento $=$ INDICADOR DE SUCESSO DE PLANEJAMENTO

Total de respostas em relação à avaliação do planejamento

2. Foco na qualidade acadêmica

(2.1)

Média anual no ano anterior = INDICADOR DE RENTABILIDADE ACADÊMICA

Média anual no ano de desenvolvimento de trabalhos no programa

(2.2)

NIVEL DE SATISFAÇÃO DOS DOCENTES = INDICADOR DE ACEITAÇÃO ACADÊMICA

(a) plenamente satisfeito, (b) satisfeito, (c) satisfeito com ressalvas, (d) insatisfeito com sugestões, (e) totalmente insatisfeito

(2.3)

NÍVEL DE SATISFAÇÃO DOS DISCENTES = INDICADOR DE ACEITAÇÃO DISCENTE

(a) excelente (b) muito boa (c) boa (d) regular (e) delicada

3. Foco no processo

(3.1) 
Respostas positivas para a avaliação da instrumentação e seguimento do programa = INDICADOR DE Total de respostas em relação à instrumentação e seguimento do programa $=$ EFICIENNCIA DO ACOMPANHAMENTO

\section{Foco nos resultados}

(4. 1)

$\%$ de Metodologia trabalhada em relação às especificidades da área de atuação $=$ INDICADOR DE APREENSÃO METODOLÓGICA DISCENTE

Em relação a este indicador, como os alunos estagiam em laboratórios com características distintas (áreas de humanas, exatas e biológicas), deve haver uma adequação da pontuação para cada área, e o índice será construído a partir do percentual de concordância entre a categorização dada pelo orientador e a categorização indicada pelo aluno.

(4.2)

Alunos selecionados $=$ INDICADOR DE SUCESSO DISCENTE

Alunos concluintes

Alunos que apresentaram trabalhos $=$ INDICADOR DE PRODUTIVIDADE DISCENTE

Total de alunos no programa

(4.4)

Carga horária cumprida $=$ INDICADOR

DE INVESTIMENTO DISCENTE

Carga horária pretendida

(4.5)
Em relação às questões abertas, estas devem ser apreciadas por uma análise de conteúdo simplificada. A análise de conteúdo, sugerida por Bardin (1977), faz um vasto estudo acerca da riqueza do léxico, através do reconhecimento de Verbos, Substantivos, Adjetivos e Palavras-Instrumento. Aqui, sugerimos que sejam retirados das respostas das questões abertas verbos, substantivos e adjetivos, divididos em dois grupos:

\begin{tabular}{|l|l|}
\hline & \\
\hline Notações Favoráveis & Notações Desfavoráveis \\
\hline
\end{tabular}

Quadro 1

(4.6)

Respostas positivas para a avaliação da eficácia e eficiência do programa $=$ INDICADOR

Total de perguntas para a avaliação da eficácia e eficiência do programa DE CONTEXTUALIZAÇÃO SOCIAL DO PROGRAMA

\section{Tabulação dos dados: valores sugeridos para os indicadores}

As pontuações abaixo foram desenvolvidas a partir dos exames de indicadores de Boclin (2002), com modificações.

Pontuação Sugerida para os Indicadores de Foco nos insumos

(1.1) INDICADOR DE ATRATIVIDADE

\begin{tabular}{|l|c|c|}
\hline $0 \%$ a $1 \%$ & INSUFICIENTE & 0 \\
\hline $2 \%$ a $4 \%$ & REGULAR & 1 \\
\hline $5 \%$ a $10 \%$ & BOM & 2 \\
\hline ACIMA DE $10 \%$ & MUITO BOM & 5 \\
\hline
\end{tabular}

Quadro 2 
Os baixos valores percentuais relativos ao interesse demonstrado reportam-se ao fato de que esta população alvo tem freqüentemente atividades extraclasses imputadas pelos familiares ou por vontade própria, havendo uma resistência de abandono destas atividades para investir em um estágio precoce, segundo a idéia vigente. Devem ser levadas em consideração ainda a natureza das vagas disponíveis e as áreas do conhecimento atendidas, assim como o número de vagas oferecidas, que são decisivos no engajamento do aluno em um processo seletivo.

(1.2) INDICADOR DE SUCESSO DE PLANEJAMENTO

\begin{tabular}{|l|c|c|}
\hline $0 \%$ a $40 \%$ & INSUFICIENTE & 0 \\
\hline $41 \%$ a $60 \%$ & REGULAR & 1 \\
\hline $61 \%$ a $80 \%$ & BOM & 2 \\
\hline ACIMA DE $80 \%$ & MUITO BOM & 5 \\
\hline
\end{tabular}

Quadro 3

primeiro intervalo é propositalmente maior do que os demais, baseando-se no fato de que o planejamento deve ter um mínimo de cobertura para poder ser feita a implantação do projeto de trabalho, do contrário estará fadado ao insucesso. Este indicador é fundamental para correções de rota do planejamento, devendo, portanto, ser rigoroso em seu diagnóstico.

Pontuação Sugerida para os Indicadores de Foco na qualidade acadêmica

(2.1) INDICADOR DE RENTABILIDADE ACADÊMICA

\begin{tabular}{|l|c|c|}
\hline $0 \%$ a $10 \%$ & FRACA & 0 \\
\hline $11 \%$ a $20 \%$ & REGULAR & 2 \\
\hline $21 \%$ a $30 \%$ & BOA & 3 \\
\hline ACIMA DE $30 \%$ & MUITO BOA & 5 \\
\hline
\end{tabular}

Quadro 4

Levando em consideração o fato de que alunos que se engajam neste programa devem a priori apresentar um bom rendimento escolar, acreditamos que o aumento da média possa ser creditado ao aprimoramento da metodologia científica, no sen- tido de fazer o aluno-estagiário aprender a aprender, um dos pressupostos das recomendações da UNESCO.

(2.2) INDICADOR DE ACEITAÇÃO ACADÊMICA

\begin{tabular}{|l|c|c|}
\hline $0 \%$ a $20 \%$ (a) ou (b) & RUIM & 0 \\
\hline $21 \%$ a $40 \%$ (a) ou (b) & FRACA & 1 \\
\hline $41 \%$ a $60 \%$ (a) ou (b) & REGULAR & 2 \\
\hline $61 \%$ a $80 \%$ (a) ou (b) & BOA & 3 \\
\hline ACIMA DE $80 \%$ (a) ou (b) & MUITO BOA & 5 \\
\hline
\end{tabular}

Quadro 5 
Este indicador, assim como o seguinte, refere-se à questão relacionada ao intercâmbio entre os diferentes níveis de ensino, de modo a se checar o quanto um e outro nível atendem às expectativas recíprocas.

(2.3) INDICADOR DE ACEITAÇÃO DISCENTE

\begin{tabular}{|l|c|c|}
\hline $0 \%$ a $20 \%$ (a) ou (b) & RUIM & 0 \\
\hline $21 \%$ a $40 \%$ (a) ou (b) & FRACA & 1 \\
\hline $41 \%$ a $60 \%$ (a) ou (b) & REGULAR & 2 \\
\hline 61\% a $80 \%$ (a) ou (b) & BOA & 3 \\
\hline ACIMA DE $80 \%$ (a) ou (b) & MUITO BOa & 5 \\
\hline
\end{tabular}

Quadro 6

Pontuação Sugerida para o Indicador de Foco no processo
(3.1) INDICADOR DE EFICIÊNCIA DO ACOMPANHAMENTO

\begin{tabular}{|l|c|c|}
\hline $0 \%$ a $40 \%$ & INSUFICIENTE & 0 \\
\hline $41 \%$ a $60 \%$ & REGULAR & 5 \\
\hline $61 \%$ a $80 \%$ & BOM & 10 \\
\hline ACIMA DE $80 \%$ & MUITO BOM & 15 \\
\hline
\end{tabular}

Quadro 7

As respostas de cunho positivo indicam o atendimento às expectativas em relação à infra-estrutura de apoio ao programa no seu desenrolar ao longo do ano.
Pontuação Sugerida para os Indicadores de Foco nos resultados

(4.1) INDICADOR DE APREENSÃO METODOLÓGICA DISCENTE

\begin{tabular}{|l|c|c|}
\hline $0 \%$ a $30 \%$ & FRACA & 0 \\
\hline $31 \%$ a $50 \%$ & REGULAR & 2 \\
\hline $51 \%$ a $70 \%$ & BOA & 3 \\
\hline ACIMA DE $70 \%$ & MUITO BOA & 5 \\
\hline
\end{tabular}

\section{Quadro 8}

Este indicador refere-se quantitativamente, em termos estatísticos no conjunto dos alunos, à compreensão da metodologia própria de cada área do conhecimento, de modo a uma utilização pertinente das técnicas de pesquisa. (4.2) INDICADOR DE SUCESSO DISCENTE

\begin{tabular}{|l|c|c|}
\hline $0 \%$ a $30 \%$ & FRACO & 0 \\
\hline $31 \%$ a $50 \%$ & REGULAR & 2 \\
\hline $51 \%$ a $70 \%$ & BOM & 3 \\
\hline ACIMA DE $70 \%$ & MUITO BOM & 5 \\
\hline
\end{tabular}

Quadro 9 
$O$ resultado individual reflete a persistência e o investimento do aluno, assim como sua maturidade em reconhecer a necessidade de um aprimoramento intelectual ao longo de sua vida, tanto pessoal quanto profissional, ao atender às exigências acordadas no processo seletivo e que culminou em seu ingresso no Programa. Já o indicador em si espelha o acerto do Programa em re- lação à alocação dos alunos-estagiários de forma correta e pertinente de acordo com o perfil traçado, tanto na solicitação por parte dos pesquisadores-orientadores quanto pela indicação feita pelos coordenadores, que encaminham os alunos aos respectivos laboratórios.

(4.3) INDICADOR DE PRODUTIVIDADE DISCENTE

\begin{tabular}{|l|c|c|}
\hline $0 \%$ a $30 \%$ & FRACA & 0 \\
\hline $31 \%$ a $50 \%$ & REGULAR & 2 \\
\hline $51 \%$ a $70 \%$ & BOA & 3 \\
\hline ACIMA DE $70 \%$ & MUITO BOA & 5 \\
\hline
\end{tabular}

Quadro 10

Indicador de forte tendência qualitativa, envolvendo esforço e dedicação do aluno em investir precocemente em produção de conhecimento.

(4.4) INDICADOR DE INVESTIMENTO DISCENTE

\begin{tabular}{|l|c|c|}
\hline $0 \%$ a $30 \%$ & FRACO & 0 \\
\hline $31 \%$ a $60 \%$ & REGULAR & 2 \\
\hline $61 \%$ a $90 \%$ & BOM & 3 \\
\hline ACIMA DE $90 \%$ & MUITO BOM & 5 \\
\hline
\end{tabular}

Quadro 11

Reflete, assim como o indicador de sucesso discente, o investimento pessoal e do grupo de alunos envolvidos no Programa para cumprimento das normas propostas e aceitas por

eles quando de sua integração ao Programa.

(4.5) INDICADOR DE SATISFAÇÃO PESSOAL

\begin{tabular}{|l|c|c|}
\hline $0 \%$ a $20 \%$ de notações favoráveis & RUIM & 0 \\
\hline $21 \%$ a $40 \%$ & FRACA & 1 \\
\hline $41 \%$ a $60 \%$ & REGULAR & 2 \\
\hline $61 \%$ a $80 \%$ & BOA & 3 \\
\hline ACIMA DE $80 \%$ & MUITO BOA & 5 \\
\hline
\end{tabular}

Quadro 12 
Aliado aos indicadores de aceitação discente e docente, este indicador refere-se ao nível de acertos na escolha da área de trabalho, informando ainda sobre as relações interpessoais estabelecidas no ambiente de trabalho, importantes no desenvol- vimento das atividades rotineiras e dos eventos adicionais (participação em congressos e jornadas, excursões, etc.).

(4.6) INDICADOR DE CONTEXTUALIZAÇÃO SOCIAL DO PROGRAMA

\begin{tabular}{|l|c|c|}
\hline $0 \%$ a $30 \%$ & FRACA & 0 \\
\hline $31 \%$ a $50 \%$ & REGULAR & 2 \\
\hline $51 \%$ a $70 \%$ & BOA & 3 \\
\hline ACIMA DE $70 \%$ & MUITO BOA & 5 \\
\hline
\end{tabular}

Quadro 13

Atendendo pressupostos da legislação, que reza que a Universidade deve prestar serviços à comunidade, a aceitação por parte da comunidade escolar e de seu entorno enfatiza os rumos, se corretos ou não, que o Programa tem tomado, daí a necessidade de um indicador que reflita esta posição.

\begin{tabular}{|l|c|l|l|}
\hline FOCO & PONTUAÇÃO ESPERADA & PONTUAÇÃO OBTIDA & PERCENTUAL \\
\hline Insumos & 10 & & \\
\hline Qualidade & 15 & & \\
\hline Acadêmica & 15 & & \\
\hline Processo & 30 & & \\
\hline Resultados & 70 & & \\
\hline Totais & 15 & & \\
\hline
\end{tabular}

Quadro 14 - Exame da pontuação obtida.

\section{Discussão e conclusões}

A metodologia é a forma de se encontrar os caminhos necessários para o auto-aprendizado em que o indivíduo é agente do processo, aprendendo a pesquisar e a sistematizar o conhecimento adquirido. Consiste em estudar e avaliar os métodos disponíveis, identificando suas limitações em nível das implicações de sua utilização; examina e avalia as técnicas de pesquisa, bem como a geração ou verificação de novos métodos que conduzem à captação e processamento da informação com vistas à resolução de problemas de investigação.
A educação pela pesquisa é a especialização mais própria da educação escolar e acadêmica e a necessidade de fazer da pesquisa atitude cotidiana no professor e no aluno. Por meio do uso de método, o aluno, o professor e o pesquisador conseguem um contato mediador do conhecimento mediante o questionamento construtivo e reconstrutivo do objeto de pesquisa, possibilitando a colocação do saber no plano sócio-histórico e políico. Como afirma Damasceno (2002, p. 17), "cabe destacar que a formação de novos pesquisadores é concebida como um processo que se integra à vida acadêmica, e não apenas como uma atividade livresca baseada na acumulação de informação". 
Um dos objetivos da aprendizagem é descrever os resultados adequados às expectativas a serem produzidas em uma unidade de instrução e de conteúdo desenvolvido, o que depende de um processo em que professor e aluno se relacionam em um sistema educacional. Através deste mecanismo pretende-se assegurar a autonomia cultural própria à investigação, à pesquisa, ao questionamento e à solução de problemas que garantem a auto-identificação e a autodeterminação social e política dos grupos sociais.

A tônica da descoberta se dá através do ensinar pesquisando e do pesquisar aprendendo. $\bigcirc$ estudante assume sua própria forma de estudar por meio de reflexões pessoais que o orientam a ter formas mais eficientes de apreensão.

A avaliação dos resultados do ensinoaprendizagem é de grande relevância porque pode tanto proporcionar informações fundamentais para o processo de tomada de decisões (administração escolar, planejamento curricular, etc.) quanto melhorar o processo ensino-aprendizagem (planejamento do ensino, atividades na sala de aula, etc.).

Stake (1967 apud TURRA et al., 1989), afirma que a avaliação educacional tem seu aspecto formal e informal. Reconhece o aspecto informal da avaliação em sua dependência dos objetivos implícitos, das normas intuitivas e dos julgamentos subjetivos. $\bigcirc$ aspecto formal da avaliação encontra-se evidenciado em sua dependência dos objetivos precisamente formulados, das comparações controladas, dos instrumentos fidedignos.

Variam os entendimentos do que seja avaliação, conforme o enfoque com que o criador do conceito a visualiza. Assim, na literatura sobre o assunto, são encontrados diversos significados atribuídos à "avaliação educacional". Algumas concepções enfatizam a dimensão "medida", enquanto outras estão mais voltadas para o aspecto de "julgamento", ou juízo de valor, enquanto outras, ainda, permeiam as duas dimensões:

Avaliação em educação significa descrever algo em termos de atributos selecionados e julgar o grau de aceitabilidade do que foi descrito. $O$ algo, que deve ser descrito e julgado, pode ser qualquer aspecto educacional, mas é, tipicamente: (a) um programa escolar, (b) um procedimento curricular ou (c) o comportamento de um indivíduo ou de um grupo. (THORNDIKE; HAGEN, 1960 apud TURRA et al., 1989).

A avaliação significa atribuir um valor a uma dimensão mensurável.

Avaliação educativa é um processo complexo que começa com a formulação de objetivos e requer a elaboração de meios para obter evidência de resultados, interpretação dos resultados para saber em que medida foram os objetivos alcançados e formulação de um juízo de valor. (SARUBBI, 1971 apud TURRA etal., 1989).

São funções gerais da avaliação: fornecer as bases para o planejamento; possibilitar a seleção e a classificação de pessoal (professores, alunos, especialistas, etc.); ajustar políticas e práticas curriculares e são funções específicas da avaliação: facilitar o diagnóstico(diagnóstico); melhorar a aprendizagem e o ensino(controle); estabelecer situações individuais de aprendizagem e promover, agrupar alunos (classificação). 
Belloni e outros (2001) supõem uma definição de avaliação como sendo um processo sistemático que busca subsídios para a melhoria da qualidade da instituição», e destacam também apenas três aspectos no contexto de avaliação vivida no país neste momento: é «processo», é «sistemático» e é «subsídio». A avaliação sozinha não melhora nem aperfeiçoa nada. Ela fornece subsídios para quem souber ler os resultados e deles extrair proposições, encaminhar a melhoria, no contexto, nas condições, nas limitações da instituição que está sendo avaliada. Segundo Boclin (2002), uma extensa lista de variáveis e indicadores tem basicamente a função de exemplificar o modelo e abrir possibilidades de construção de novos indicadores. Lembra ainda que certos indicadores devem ser adotados não para efeito comparativo, mas para pontuar um critério no sentido de aprimorar seu desempenho. Ter-se-á, conseqüentemente, um aprimoramento do programa, que reverte para seus usuários, aqui especificamente alunos do ensino médio, colaborando assim para a melhoria do ensino e ingresso, no nível superior, de alunos mais bem preparados, com uma visão crítica, dada pelo saber aprender.

\section{Referências}

AGUILAR, M. J.; ANDER-EGG, E. Avaliação de serviços e programas sociais. Petrópolis: Vozes, 1994.

BARDIN, L. Análise de conteúdo. Lisboa: Edições 70, 1977.

BELLONI, I.; MAGALHÃES, H.; SOUSA, L. C. Metodologia de avaliação em políticas públicas. 2. ed. São Paulo: Cortez, 2001.

BOCLIN, R. G. O uso de indicadores de desempenho na avaliação institucional: quem acredita?. 2002. Tese (Doutorado em Educação)-Faculdade de Educação, Universidade Federal do Rio de Janeiro, Rio de Janeiro, 2002.

BRASIL. Lei no 9.394, de 20 de dezembro de 1996. Estabelece as diretrizes e bases da educação nacional. Diário Oficial [da] República Federativa do Brasil. Brasília, DF, 23 dez. 1996.

DAMASCENO, M. N. A formação de novos pesquisadores: a investigação como uma construção coletiva a partir da relação teoria-prática. In: CALAZANS, M. J. (Org.). Iniciação científica: construindo o pensamento crítico. 2. ed. São Paulo: Cortez, 2002.

DELORS, J. (Org.). Educação: um tesouro a descobrir. Brasília, DF: UNESCO, 2003. PARÂMETROS Curriculares Nacionais: ensino médio. Brasília, DF: Ministério da Educação, Secretaria de Educação Média e Tecnológica, 1999. v.1.

PATTON, M. Q. Utilization-focused evaluation. Newbury Park, CA: Sage, 1986. TURRA, D. E.; SANT'ANNA, F. M.; ANDRÉ, L. C. Planejamento de ensino e avaliação. 11. ed. Porto Alegre: Sagra, 1989.

Recebido em: 25/01/2007

Aceito para publicação em: 09/02/2007 


\section{ANEXOS}

\section{FICHA DE AVALIAÇÃO DE PLANEJAMENTO, ACOMPANHAMENTO E RESULTADOS}

Segundo o planejamento e estudos iniciais para implantação, implementação e acompanhamento do Programa, as seguintes questões, sugeridas por Aguilar e Ander-Egg (1994) devem ser respondidas, pe los coordenadores do Programa, para obtenção dos indicadores: (1) de sucesso do planejamento, (2) de eficiência do acompanhamento do programa e (3) de contextualização social do programa.

\section{Perguntas para a avaliação do sucesso do planejamento e conceituação do programa}

\section{a) Avaliação do estudo-pesquisa}

1- Foi claramente delimitado o universo ou a população a estudar?

( ) $\operatorname{sim}($ ) não

2- Foram adequados os procedimentos de amostragem?

( ) $\operatorname{sim} \quad($ ) não

\section{b) Avaliação do diagnóstico}

1- Foram claramente estabelecidas a natureza e magnitude dos problemas e necessidades?

( ) SIM ( ) NÃO

2- Foi feito um prognóstico realista?

( ) SIM ( ) NÃO

3- Foi feita uma análise da viabilidade política das possíveis intervenções?

( ) SIM ( ) NÃO

4- Foi estabelecido um perfil do usuário ou beneficiário?

( ) SIM ( ) NÃO

5- Pode-se conseguir que um programa funcione num determinado contexto?

( ) SIM ( ) NÃO

c) Avaliação do plano do programa

1- O programa foi planejado para alcançar os objetivos propostos?

( ) SIM ( ) NÃO

3- Foram maximizadas as possibilidades de que o programa chegue sem problemas aos usuários ou beneficiários potenciais?

( ) SIM ( ) NÃO

4- Existe coerência entre o programa elaborado e os resultados do diagnóstico? O programa responde às necessidades e problemas detectados no diagnóstico?

( ) SIM ( ) NÃO

5- Que relação tem o programa com a política geral da instituição?

( ) ATENDE AOS PARÂMETROS ( ) NÃO ATENDE AOS PARÂMETROS

6- Foram fixados objetivos e metas a curto, médio e longo prazo?

( ) SIM ( ) NÃO

7- Respondem os objetivos e metas às necessidades e problemas detectados?

( ) SIM ( ) NÃO

8- Até que ponto o "programado" ajudará a resolver, de uma forma significativa, a necessidade para cuja superação foi elaborado o programa?

( ) PLENAMENTE

( ) DE MODO PRECÁRIO ( ) DE MODO INSUFICIENTE

( ) SUFICIENTEMENTE

9- As atividades foram relacionadas com os objetivos e as metas?

( ) SIM ( ) NÃO

10- Foi especificado um calendário de execução?

( ) SIM ( ) NÃO

11- Foram previstos recursos suficientes e em tempo oportuno para alcançar os objetivos e metas propostas?

( ) SIM ( ) NÃO

12- Qual o respaldo real do programa da parte dos dirigentes políticos e técnicos da instituição?
( ) PLENO
) PRECÁRIO
( ) SATISFATÓRIO
( ) INSUFICIENTE
( ) SUFICIENTE

13- Foram feitos uma adequada estrutura financeira e calendário financeiro do programa?

( ) SIM ( ) NÃO

14- Foi prevista uma estrutura de gestão do programa?

( ) SIM ( ) NÃO

15- Foram especificados no plano do programa os indicadores de avaliação de resultados e as fontes e meios de comprovação desses indicadores?
( ) SIM
( ) NÃO 


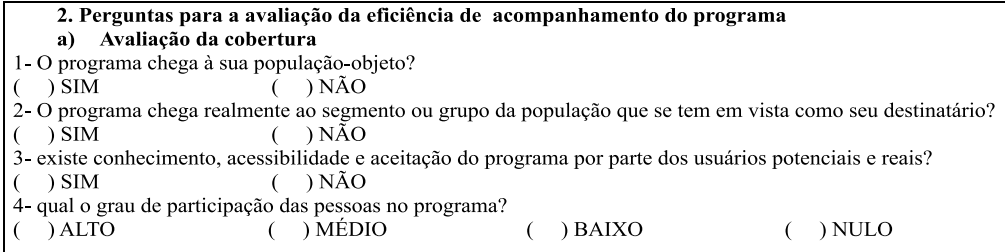

b) Avaliação da implementação e seguimento

1- O programa é implementado como estava previsto no plano?

( ) SIM ( ) NÃO

2- Foram postos em prática os esforços de intervenção na forma indicada no plano do programa? As atividades e tarefas são executadas do modo previsto?

( ) SIM ( ) NÃO

3- Foram cumpridas as tarefas de preparação e motivação necessárias para criar um clima favorável à implantação do programa?

( ) SIM ( ) NÃO

4- Existe um adequado sistema de controle operacional sobre o andamento do programa?

( ) SIM ( ) NÃO

5- Existe um adequado sistema de informação para o seguimento do programa?

( ) SIM ( ) NÃO

6- Os recursos estão sendo utilizados adequadamente?

( ) SIM ( ) NÃO

7- Os procedimentos utilizados são apropriados aos objetivos em vista? Facilitam a consecução desses objetivos?

( ) SIM ( ) NÃO

8- Os procedimentos utilizados são oportunos do ponto de vista político, econômico, social, cultural e/ou institucional?

( ) SIM ( ) NÃO

c) Avaliação do rendimento do pessoal

1- Qual é a aptidão e habilidade do pessoal na aplicação de técnicas e procedimentos às tarefas e atividades próprias de seu trabalho?

( ) ALTA ( ) MÉDIA ( ) BAIXA ( ) NULA

2- A competência profissional do pessoal do programa se ajusta aos padrões de qualidade exigidos?

( ) SEMPRE ( ) FREQÜENTEMENTE ( ) SUFICIENTEMENTE

( ) RARAMENTE ( ) NUNCA

3- Qual a capacidade do pessoal para organizar o trabalho e resolver problemas?

( ) ALTA ( ) MÉDIA ( ) BAIXA ( ) NULA

4- O pessoal possui os conhecimentos e habilidades necessárias para o correto desempenho das funções a seu cargo? E as aptidões?

( ) SEMPRE ( ) FREQÜENTEMENTE ( ) SUFICIENTEMENTE

( ) RARAMENTE ( ) NUNCA

( ) RARAMENTE ( ) NUNCA

5- O pessoal desempenha suas funções e atividades no tempo oportuno?

6- Qual é o nível de satisfação do pessoal do programa?

( )ALTA ( ) MÉDIA $\quad(\quad)$ BAIXA $\quad$ ( ) NULA

7- Existem incentivos para o pessoal?

( ) SIM ( ) NÃO

d) Avaliação da estrutura e ambiente organizacional

1- A estrutura organizacional da instituição contribui ou prejudica o desenvolvimento do programa?

( ) CONTRIBUI ( ) PREJUDICA

2- A natureza e o conteúdo das comunicações internas do programa se adaptam às necessidades de gestão do mesmo?

( ) SIM ( ) NÃO

3- A natureza e o conteúdo das comunicações internas do programa são suficientes, excessivas ou escassas?

( ) SUFICIENTES ( ) EXCESSIVAS ( ) ESCASSAS

4- As modalidades de coordenação permitem articular adequadamente as atividades das diferentes pessoas implicadas na realização do programa ou na prestação do serviço?

( ) SIM
( ) NÃO

\section{Perguntas para a avaliação da contextualização social do programa}

a) Avaliação de resultados ou avaliação da eficácia do programa

1- O programa é efetivo quanto à consecução dos objetivos que são perseguidos?

( ) SIM ( ) NÃO

2- Como se modificou a situação dos usuários ou beneficiários do programa?

( ) SIGNIFICATIVAMENTE ( ) DE MODO POUCO SIGNIFICATIVO ( ) NÃO SE MODIFICOU

3- A ações postas em prática foram úteis, benéficas ou nocivas?

( ) ÚTEIS ( ) BENÉFICAS ( ) NOCIVAS

4- O resultados do programa podem ser atribuídos a processos alternativos exógenos a ele?

( ) SIM ( ) NÃO

5- Qual é a opinião dos usuários e não usuários acerca do programa?

( ) EXCELENTE ( ) MUITO BOM ( ) BOM

( ) REGULAR ( ) RUIM 


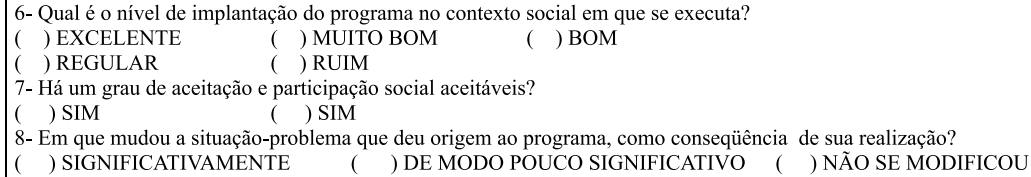

\section{FICHA DE LEVANTAMENTO DE DADOS - ESTAGIÁRIO}

\section{Nome:}

Laboratório/Sala de Estágio:

Prof. Orientador:

Projeto Desenvolvido:

Carga Horária Total do Estágio Realizado:

Carga Horária cumprida pelo Estagiário:

Metodologia de busca e sistematização de informações utilizada (numerar em ordem crescente de freqüência no trabalho realizado):

( ) confecção de tabelas ( ) confecção de gráficos

( ) resumos de textos ( ) fichamento de livros

( ) pesquisa em bibliotecas ( ) pesquisa na $\mathrm{Web}$

( ) confecção de relatórios ( ) uso de técnicas laboratoriais

( ) leitura de textos técnicos aplicados da área específica

( ) leitura de textos básicos de fundamentação teórica da área específica

Trabalhos Desenvolvidos

( ) relatório de conclusão de estágio ( ) apresentação de trabalho(s) em jornadas científicas e congressos

Título(s) do(s) trabalho(s) apresentado(s):

Relação estabelecida:

a) com o Orientador:

b) com a equipe da sala/laboratório:

( ) excelente ( ) muito boa

c) com o pessoal de apoio técnico-administrativo:

( ) excelente ( ) muito boa ( ) boa ( ) regular $\quad($ ) delicada

Impressões sobre seu desempenho pessoal no estágio: 


\section{FICHA DE LEVANTAMENTO DE DADOS INDIVIDUAIS -}

\section{SETOR DE ORIENTAC ̃̃O EDUCACIONAL}

Aluno Avaliado:

Técnico Responsável:

\section{DADOS ACADÊMICOS}

Impressões sobre a relação estabelecida pelo aluno ao longo do Estágio:

a) com a Equipe Pedagógica:

() com a Equipe

b) com o Corpo Docente:

( ) excelente

c) com a turma:

( ) muito boa

( ) boa

( ) regular

( ) delicada

( ) excelente

( ) muito boa

( ) boa

( ) regular

( ) delicada

( ) muito boa

( ) boa

( ) regular

( ) delicada

Atitudes desenvolvidas observadas pelo estagiário ao longo do trabalho em relação às atividades acadêmicas:

( ) assiduidade e interesse

( ) melhoria do rendimento escolar

( ) participação ativa nas atividades propostas na escola

Média Anual (Coeficiente de Rendimento) do Estagiário:

a) ao final do ano letivo anterior ao estágio

b) ao final do ano letivo em que desenvolveu o estágio

Impressões sobre o desempenho comportamental do Estagiário:

\section{FICHA DE LEVANTAMENTO DE DADOS GERAIS - COORDENADOR DE ESTÁGIO}

Nome:

Área de Concentração de Origem:

Cargo na Unidade Escolar:

Alunos matriculados na série em que se dá o processo seletivo:

Alunos que se candidataram ao processo seletivo:

Alunos selecionados para o Estágio:

Alunos concluintes do Estágio:

Participação efetiva dos alunos candidatos das atividades propostas ao longo do processo seletivo:

$\begin{array}{lll}\text { ( ) excelente } & (\text { ) muito boa } & (\text { ) boa }\end{array}$

$(100 \%) \quad($ entre 80 e $90 \%) \quad$ (entre 60 e $80 \%) \quad$ (entre 50 e $60 \%)$

Expectativas sobre o desempenho dos alunos no início e ao término do estágio em ordem de relevância:

( ) desenvolvimento de senso de responsabilidade

( ) melhora no rendimento escolar

( ) melhora no relacionamento social com os colegas

( ) aumento da capacidade de concentração nas atividades acadêmicas propostas

( ) aumento do nível de maturidade em discussões de cunho social

( ) outros (especificar):

Nível de Atendimento das Expectativas e correlação com o Projeto Político Pedagógico da Instituição: 


\section{FICHA DE LEVANTAMENTO DE DADOS - ORIENTADOR}

Nome:

Laboratório/Sala de Estágio:

Departamento/Instituto:

Centro:

Titulação:

Estagiário:

Carga Horária proposta do Estágio Realizado:

Carga Horária cumprida pelo Estagiário:

Metodologia de Pesquisa pretendida (numerar em ordem crescente de freqüência e relevância no trabalho realizado):

( ) confecção de tabelas ( ) confecção de gráficos

( ) resumos de textos ( ) fichamento de livros

( ) pesquisa em bibliotecas ( ) pesquisa na $\mathrm{Web}$

( ) confecção de relatórios ( ) uso de técnicas laboratoriais

( ) leitura de textos técnicos aplicados da área específica

( ) leitura de textos básicos de fundamentação teórica da área específica

Impressões sobre a relação estabelecida pelo aluno:

a) com o Orientador:
( ) excelente
( ) muito boa
( ) boa ( ) regular
( ) delicada
b) com a equipe da sala/laboratório:
( ) excelente com o pessoal de apoio técnico-administrativo:
( ) excelente
( ) muito boa
( ) boa ( ) regular
( ) delicada
( ) boa ( ) regular
( ) delicada

Atitudes desenvolvidas observadas pelo orientador no estagiário ao longo do trabalho:
( ) assiduidade e interesse
( ) rendimento compatível com o esperado
( ) participação ativa nas atividades propostas
( ) efetivo aproveitamento no desenvolvimento dos trabalhos propostos

Nível de Satisfação com o trabalho realizado pelo Estagiário:
( ) plenamente satisfeito
( ) satisfeito
( ) insatisfeito com sugestões
( ) totalmente insatisfeito
( ) satisfeito com ressalvas

Impressões sobre o desempenho do Estagiário: 